\title{
Speaking up for the telephone
}

\author{
Next week sees the centenary of the telephone. Below, \\ a look at telecommunications in Britain
}

TT MAY be going too far to suggest

$\boldsymbol{I}_{\text {that, in telecommunications, the pace }}$ of research and development may have all but outstripped our capacity to appraise and utilise it. But now more than ever (and in telecommunications more than anything) it takes specialists, in electronics and electrical engineering, to comprehend the intricacies, if not the implications, of the astonishingly broad and complex range of telecommunications "breakthroughs" in the 100 years since Alexander Graham Bell spoke seven words to his assistant on the first telephone.

Telecommunications is widely recognised in Britain as lying firmly within the public domain, being the nuts and bolts of a public service provided by the Post Office, a nationalised undertaking. The Post Office itself acknowledges this; so too does the government. And most people in Britain expect it. Yet the reality looks rather different, for the boundaries of the telecommunications industry are far from coincident with those of the British economy's public sector.

The Post Office, formerly the GPO but made a corporation in 1969, has long had a monopoly of the country's telecommunications services. The assets of the system it runs, which is the third largest in the world, are valued at over $£ 4000$ million; the Post Office is the country's biggest employer, with almost 250,000 of its 430,000 employees in telecommunications; investment in the year 1974-75 totalled $£ 788$ millions, of which $76 \%$ (about $£ 600$ millions) went on growth and the rest to maintaining and improving the existing system. The figures are enormous; but they form only part of the UK telecommunications picture.

Quite as important is the Post Office's position regarding procurement. In supplies it has nothing like a monopoly. Indeed, just last year, the Post Office produced a document containing recommendations on whether it should manufacture "in-house" more of the substantial amounts of equipment, worth hundreds of millions of pounds, which its existing suppliers produced for it. The question highlighted the network of links between the Post Office, a public corporation, and its main suppliers, all private enterprises with famous names-Plessey, GEC, Pye TMC and Standard Telephones and Cables (STC). A few months later, the nature of those links was further highlighted by announcements from all of these companies of impending mass redundancies as a consequence of a cut-back by the Post Office in its projected orders for telephone exchanges, transmission equipment and telephone sets.

The reasons behind this upset were also revealing. They related, at least in part, to a $30 \%$ reduction in the Post Office's estimate on orders for 1975-76 and 1976-77 compared to its estimate a year earlier; this reduction was in turn a reflection of declining demand in the face of rising costs which the Post Office found itself obliged to pass on under the UK government's rediscovered "profitability" regime for the public sector. But the need for redundancies would have arisen anyway, since it was also the result of the design and labour-saving manufacture of electronic exchanges being introduced to replace more conventional electromechanical exchanges and so provide the basis for a massive modernisation programme for the UK telecommunications system.

Reactions to these redundancies also showed the sort of economic factors at work, but revealed political ones too, for the additional unemployment at a time of deepening recession naturally evoked deep emotions. Calls for the introduction of the electronic exchanges to be postponed and for old order levels to be restored, if successful, would have given the Post Office too many of the wrong exchanges which it could not really afford anyway (unless it passed the costs on).

\section{Research and development}

That new technologies as well as the plight of the economy are responsible for these cut-backs is just one indication of the central role which research and development plays in British telecommunications. There are others, of course, but a glance at the Post Office's books is sufficient to confirm its importance. In 1974-75, expenditure by the Post Office on research and development climbed fully $30 \%$ in value to £28.9 millions. Even more striking. about $93 \%$ of this ( $£ 27.1$ million) was devoted to telecommunications, divided as follows: $59 \%$ ( $£ 16.1$ millions) on "new systems", $25 \%$ (£6.8 millions) on "existing systems and related advisory services", and the rest ( $£ 4.2$ millions) on exploratory research.

A Science Research Council publication released in 1974, surveying current research activities in the UK, says Post Office research and development then involved "some 3,500 staff, of

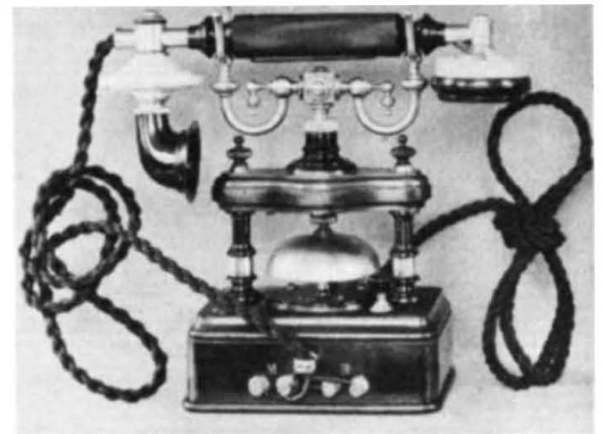

whom about 1,000 are qualified scientists or engineers". The Research Department, now located at Martlesham, the new research centre opened last year, conducts exploratory research into new systems and services as well as the technology, materials and devices to back them up; the Development Department elaborates this work, which focuses chiefly on "switching" (exchanges) and transmission.

Important as it is, however, the Post Office's teams are not the only ones in operation even amongst the public corporations. Work is also done by both broadcasting networks (the BBC and the IBA) and by British Rail. Furthermore, there is the mostly-secret Ministry of Defence activity, through the Signals Research and Development Establishment, the Admiralty Surface Weapon Establishment and the Royal Aircraft Establishment; and the SRC has its own Appleton Laboratory. Each of the Post Office's main suppliersmajor companies all-also has sizeable research facilities, on a scale similar to that of the Signals Research and Development Establishment. The work done in these is, the SRC says, undoubtedly influenced by the Post Office, because it is their major customer; between them, in fact, they share several hundred million poinds worth of Post Office business annually. Finally, there are the universities and polytechnics, whose work involved (in 1972-73) 526 people and an expenditure of almost $£ 350,000$, the greatest amount coming from the public sector.

The research net is thus spread fairly wide. But what is caught in it? Practically everything conceivable and more besides, if such breakdowns by establishment as are available are anything to go by. While the jaundiced eye might cynically view those research efforts which are made glamorous by publicityconscious promoters as mere attempts at self-justification, it would probably still focus on the extensively-publicised telecommunications work of the Post Office; after all, the telephone service remains the most direct contact with the world of telecommunications for the large majority of people.

Take the humble telephone set itself. In concept the instrument has changed little: but in a new microphone, sound 
generates an electric signal from a plastic diaphram with a built-in charge which is boosted by a transistor amplifier. Do the problems of general application, which are large, make such time, money and effort worthwhile? Professor Merriman, Senior Director (Development) with Post Office Telecommunications, has explained that the benefit of such devices lies "in their implied potential for modifying the balance of investment" between telephone sets and their lines to the local exchange. Similar economic arguments are deployed regarding development of the lines themselves. But the chances of reducing costs, without a "fundamental" change in technology, are, he has argued, "reaching an asymptotic limit".

\section{Transmission and exchanges}

It is precisely such a change which offers the possibility of transforming the main transmission systems, for here research and development has progressed enormously, particularly in the last ten years. Two entirely new forms of transmission system are being developed which virtually outdate the now-customary coaxial cable and microwave systems.

One uses "optical fibres" and transmits signals in the form of light pulses down extremely thin strands of glass fibre. They can carry more messages further and more cheaply with fewer amplifiers than conventional cables. The other uses "waveguides", and is described by the Post Office as "a kind of piped microwave radio"; in it, signals are borne on waveforms down a copper pipe. In both cases digital transmission is involved, where signals are sent as a code of pulses, obtained and retranslated through what is known as pulse code modulation, rather than in the customary analogue form, where electrical waves corresponding to sound need greater boosting.

But perhaps most attention, certainly in the case of the Post Office supliers, is being devoted to "switching", or exchanges. The key electronic development which is outdating electromechanical arrangements is the integrated circuit, or "chip", hundreds of which are no larger than a pin's head: made of semiconductor, these will replace the large electromagnetic relays: linked to form "processors", they could control central as well as local exchanges. The TXE2 is smaller and uses more basic technology than the TXE4, the electronic exchange developed for large local exchanges of up to 40,000 lines. For the suppliers they offer tremendous export potential, particularly with respect to countries establishing whole new telephone systems.

Switching now represents something like a third of the Post Office's overall investment and is probably the most substantial element of the telecommunications industry's annual production. With the refinement of the electronic exchange, the development path for Britain's telephone system seems fairly clear for the rest of the decade. But it is the result of decisions taken over a period of some 15 years. Moreover, further developments in switching technology are anticipated, and soon. Their application demands foresight too; but it also demands consideration of the precise manner in which they will fit in to technological changes in signals and transmission. That means one thing if costs are to go on being reduced in the 1980s: as Merriman has put it, future switching technology "inescapably must be conceived in the context of total systems development and as part of the progressive move towards all-digital, microelectronic, software-controlled systems".

Which introduces what the Post Office calls its "System X", the catchword it proudly uses for overall modernisation of Britain's telephone system. The catchword is necessary: any explanation of it descends quickly into the jargon of systems analysis. The basic idea seems to be that a comprehensive strategy laid now by the Post Office and the industry for the future will, over the years as it is introduced on a larger and larger scale, plan and coordinate the direction of research at all levels, anticipate developments in advance which might in turn be incorporated into the strategy, and generally ensure balanced development and progress.

If the money is there. Thus far, as the figures themselves show, telecommunications has not had it all that bad: few other high technology sectors can point to coherent plans for the 1980 s so confidently. And they do not relate only to the telephone system: the list of services now or soon to be provided includes radiopaging (the doctors' "bleepers"), Viewdata (up-tothe-minute information on the telly at the push of a button), Confravision and Viewphone (long-distance conferences between individuals who can see each other and exchange papers) and Fax, or facsimile transmission (a

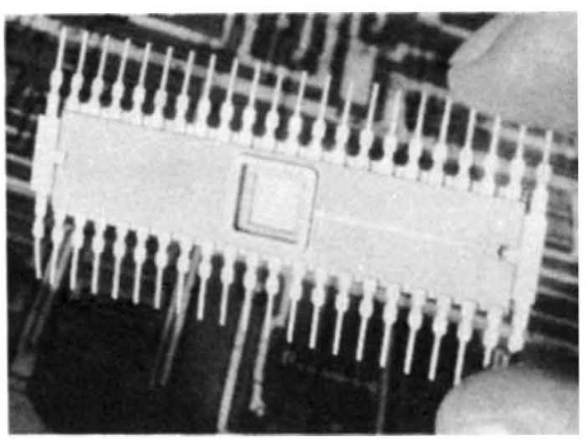

Integrated circuit for electronic exchange telex-photocopy combination). Even within the realm of telephony itself, improved international dialling and telex facilities, additional use of radio and satellites, automatic dialling devices, push button phones-all are held out, and the list goes on. Fourteen years after Telstar, in fact, space technology still represents a new frontier, and the Post Office has a share in a total of seven satellites.

In Britain, telephones have until recently proved an enormous growth area, and even last year's downturn was then regarded by the Post Office as purely temporary. There are now around 21 million telephones in the whole country. The Post Office argues that real costs to the consumer have fallen over the years, and have done so because of foresight over technological developments in transmission and exchanges. The experts, in telecommunications as in other comparable fields, wish to see the progress made thus far continue at the same if not an increased pace-partly, the cynics would say, to keep themselves in business, though also to supply a continuing demand at a reasonable cost. But projections for the hopefully rosier future can be wrong in an inflationary era. Moreover, the pace of well-financed development being what it is, if demand for various services does grow, even System X could be outdated by the time it is fully installed.

It is precisely this sort of consideration which highlights what many people regard as the real dilemma of telecommunications in Britain 100 years after the telephone: the inevitable duality of a rapid growth in telecommunications knowledge, on the one hand, and, on the other, the lengthy periods needed for appraisal and implementation. Decisions on the direction of research, on appreciation of results and on their application-the argument runs-consume inordinate amounts of time which the additional element of public accountability tends to lengthen still further. It is an argument used to press for greater competition in telecommunications services and to encourage less duplication of research. Others would like to see less research altogether and more grist to the consuming public's mill.

The end result is a mixture of efficiency and inefficiency, profit and loss, bitterness and sweetness: less something Britain can afford than something she cannot afford to be withoutand a far cry from those days over a hundred years ago when those who could conceive the idea of transmitting a voice over wires nevertheless thought it would be of little practical value. 